Kerri Wizner, MPH; Mason Harrell, MD, MPH; Manijeh Berenji, MD, MPH; Fraser W. Gaspar, PhD, MPH; Jennifer Christian, MD, MPH ReedGroup, Ltd. (Ms. Wizner and Dr. Gaspar); Boston Medical Center and Boston University School of Medicine, MA (Dr. Berenji); Webility Corporation, Wayland, MA (Dr. Christian). Dr. Harrell is an independent researcher, San Diego, CA.

\section{- kerri.wizner@} mdguidelines.com

Ms. Wizner and Dr. Gaspar are employees of ReedGroup, Ltd., which publishes disability duration guidelines and the American College of Occupational and Environmental Medicine evidence-based medical treatment guidelines.

Drs. Harrell, Berenji, and Christian reported no potential conflict of interest relevant to this article.

doi: $10.12788 / \mathrm{jfp} .0213$

\title{
Managing work disability to help patients return to the job
}

\author{
Improving the timeliness and quality of your guidance \\ on work disability lessens the impact of health problems \\ on patients' lives and livelihoods.
}

\section{PRACTICE \\ RECOMMENDATIONS}

> Set appropriate expectations for the patient at the start of any episode of work disability: Estimate the course of functional recovery over time and the total duration of life-work disruption. (A)

$>$ Include detailed activity prescriptions in the treatment plan, with stepwise progression over time toward full recovery. B

Strength of recommendation (SOR)

A Good-quality patient-oriented evidence

B Inconsistent or limited-quality patient-oriented evidence

C Consensus, usual practice opinion, disease-oriented evidence, case series
A ll clinicians who have patients who are employed play an essential role in work disability programs-whether or not those clinicians have received formal training in occupational health. A study found that primary care clinicians are asked to provide guidance about work activities in nearly $10 \%$ of their patient encounters; however, $25 \%$ of those clinicians thought they had little influence over work disability outcomes. $^{1}$

In this article, we explain why it is important for family physicians to better manage work disability at the point of care, to help patients return to their pre-injury or pre-illness level of activity.

\section{Why managing the duration} of work disability matters

Each year, millions of American workers leave their jobs-temporarily or permanently-because of illness, injury, or the effects of a chronic condition. ${ }^{2}$ It is estimated that 893 million workdays are lost annually due to a new medical problem; an additional 527 million workdays are lost due to the impact of chronic health conditions on the ability to perform at work. ${ }^{3}$ The great majority of these lost workdays are the result of personal health conditions, not work-related problems; patients must therefore cope with the accompanying disruption of life and work.

Significant injury and illness can create a life crisis, especially when there is uncertainty about future livelihood, such as an income shortfall during a lengthy recovery. Only $40 \%$ of the US workforce is covered by a short-term disability insurance program; only $10 \%$ of low-wage and low-skill workers have this type of coverage. ${ }^{4}$ Benefits rarely replace loss of income entirely, and worker compensation insurance programs provide only partial wage replacement.

In short, work disability is destabilizing and can threaten overall well-being. ${ }^{5}$ 
Furthermore, the longer a person remains on temporary disability, the more likely that person is to move to a publicly funded disability program or leave the workforce entirely-thus, potentially losing future earnings and self-identity related to being a working member of society. ${ }^{6-8}$

- Most of the annual cost of poor health for US employers derives from medical and wage benefits ( $\$ 226$ billion) and impaired or reduced employee performance (\$223 billion). ${ }^{3}$ In addition, temporarily disabled workers likely account for a disproportionate share of health care costs: A study found that one-half of medical and pharmacy payments were paid out to the one-quarter of employees requiring disability benefits. ${ }^{9}$

Benefits of staying on the job. Research shows that there are physical and mental health benefits to remaining at, or returning to, work after an injury or illness. ${ }^{10,11}$ For example, in a longitudinal cohort of people with low back pain, immediate or early return to work (in 1-7 days) was associated with reduced pain and improved functioning at 3 months. ${ }^{12}$ Physicians who can guide patients safely back to normal activities, including work, minimize the physical and mental health impact of the injury or illness and avoid chronicity. ${ }^{13}$

\section{Emphasizing the importance \\ of health, not disease or injury}

Health researchers have found that diagnosis, cause, and extent of morbidity do not adequately explain observed variability in the impact of health conditions, utilization of resources, or need for services. A wider view of the functional implications of an injury or illness is therefore required for physicians to effectively recommend disability duration.

The World Health Organization recommends a shift toward a more holistic view of health, impairment, and disability, including an emphasis on functional ability, intrinsic capacity, and environmental context. ${ }^{14}$ The American Medical Association, American College of Occupational and Environmental Medicine, and Canadian Medical Association emphasize that prolonged absence from one's normal role can be detrimental to mental, physical, and social well-being. ${ }^{8}$ These advisory groups recommend that physicians encourage patients who are unable to work to (1) focus on restoring the rhythm of their everyday life in a stepwise fashion and (2) resume their usual responsibilities as soon as possible.

Advising a patient to focus on "what you can do," not "what you can't do," might make all the difference in their return to productivity. Keeping the patient's-as well as your own-attention focused on the positive process of recovery and documenting evidence of functional progress is an important addition to (or substitute for) detailed inquiries about pain and dysfunction.

\section{Why does duration of disability vary so much from case to case?}

Disability duration is influenced by the individual patient, employer, physician, jurisdiction, insurer or benefits structure, and access to care. ${ }^{15}$ For you to effectively manage a patient who is out of work for a medical reason, it is important to understand how nonmedical variables often influence the pace of recovery and the timing of return to work (FIGURE).

Deficient communication. Often, employers, insurers, third-party administrators, and clinicians-each a key stakeholder in disability care-are disconnected from one another, resulting in poor communication with the injured worker. Such fragmented communication can delay treatment and recovery. ${ }^{16}$ Data systems are not designed to measure the duration of disability or provide proactive notification for key stakeholders who might intervene to facilitate a patient's recovery.

Alternatively, a collaborative approach to disability management has been shown to improve outcomes. ${ }^{17,18}$ Communication among the various professionals involved can be coordinated and expedited by a case manager or disability manager hired by the medical practice, the employer, or the insurance company.

- Psychosocial and economic influences can radically affect the time it takes to return to pre-injury or pre-illness functional status. Demographic variables (age, sex, income, education, and support system) influence how a person responds to a debilitating injury or
Consider that your patient's prolonged work disability and consequent loss of livelihood are very poor outcomes of a medical or health condition. 
FIGURE

Medical and nonmedical variables can influence the duration of life-work disruption

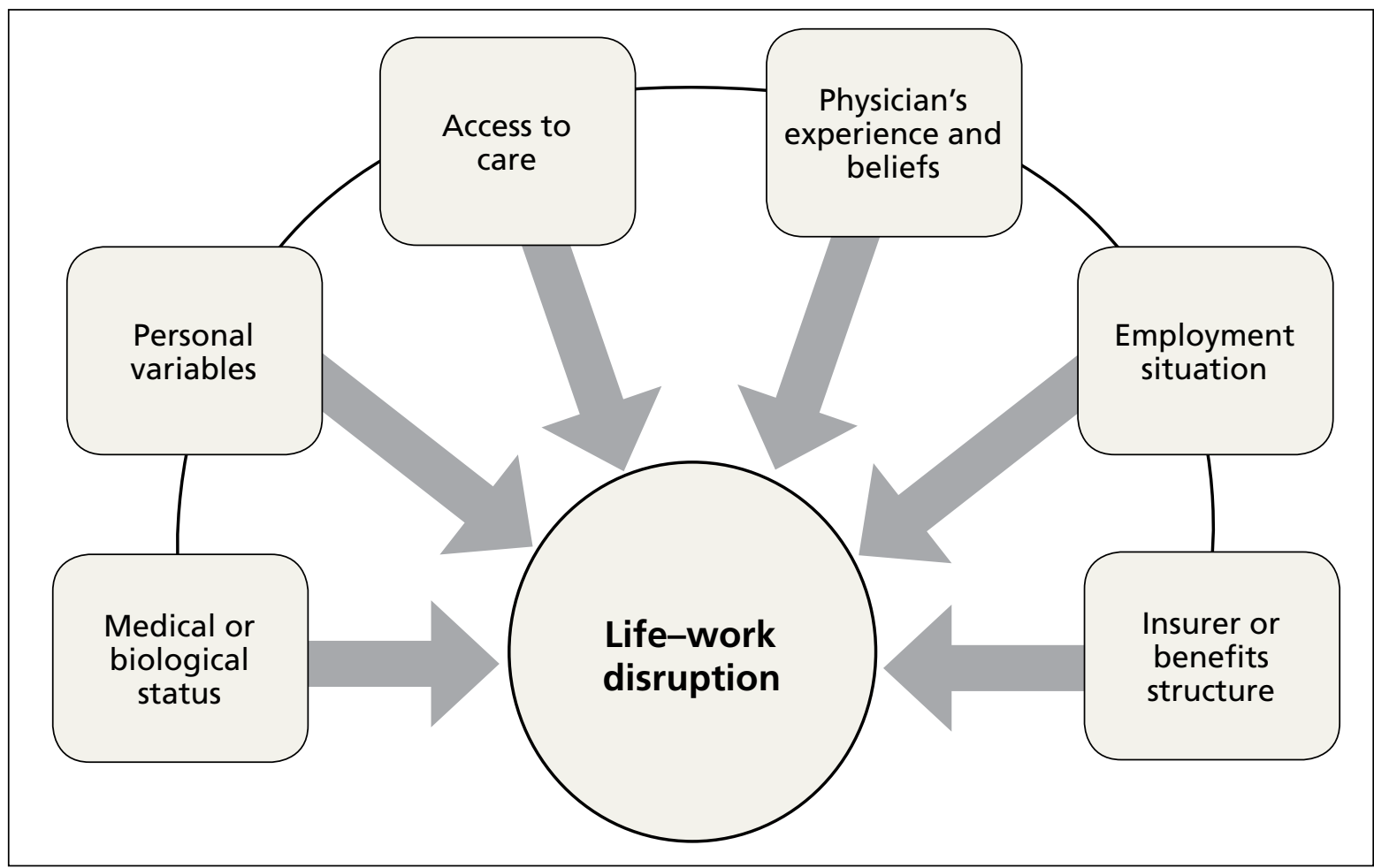

illness. ${ }^{19}$ Fear of re-injury, anxiety over the intensity of pain upon movement, worry over dependency on others, and resiliency play an important role when a patient is attempting to return to full activity. ${ }^{20,21}$

Job satisfaction has been identified as the most significant variable associated with prompt return to work. ${ }^{15}$ Work has many health-enhancing aspects, including socioeconomic status, psychosocial support, and self-identity ${ }^{22}$; however, not everyone wants, or feels ready, to go back to work even once they are physically able. Workplace variables, such as the patient-employee's dislike of the position, coworkers, or manager, have been cited by physicians as leading barriers to returning to work at an appropriate time. ${ }^{23,24}$

IOther external variables. Physicians should formulate activity prescriptions and medical restrictions based on the impact the medical condition has on the usual ability to function, as well as the anticipated impact of specific activities on the body's natural healing process. However, Rainville and colleagues found that external variablespatient requests, employer characteristics, and jurisdiction issues-considerably influence physicians' recommendations..$^{20}$ For example, benefit structure might influence how long a patient wants to remain out of workthus altering the requests they make to their physician. Jurisdictional characteristics, such as health care systems, state workers' compensation departments, and payer systems, all influence a patient's recovery timeline and time away from work. ${ }^{25}$

What does your patient need so that they can recover? Individual and systemic factors must be appropriately addressed to minimize the impact that recovery from a disability has on a person's life. Successful functional recovery enables the person to self-manage symptoms, reduce disruptionassociated stress, preserve mental health, and maintain healthy relationships at home and work. An example is the patient who has suc- 
cessfully coped with the entire predicament that their medical condition posed and resumed their usual daily routine and responsibilities at home and at work-albeit sometimes with temporary or permanent modification necessitated by their specific condition.

\section{Strategies that help patients} stay at, or return to, their job Physicians who anticipate, monitor, and actively manage the duration of a work disability can improve patient outcomes by minimizing life disruption, avoiding unnecessary medical care, and shortening the period of absence from work.

I Key strategy: Set expectations for functional recovery early in the episode, including a forecast of how long it will take to get life and work back to normal. ${ }^{26,27}$ This is similar to discussing expectations about pain before surgery, which has been shown to decrease subsequent requests for opioids. ${ }^{28}$ It is crucial to educate the patient about timelines, define functional outcomes, and encourage them to set goals for recovery. ${ }^{29}$

I Devise an evidence-based treatment plan. A fundamental way to reduce disability duration is to (1) devise a treatment plan that is evidence based and (2) take the most effective route to recovery. Given the pace with which medical research changes the understanding of diseases and treatments, it is essential to rely on up-to-date, comprehensive, independent, and authoritative resources to support your care decisions.

Aligning clinical practice with evidencebased medicine (EBM) is a good way to accomplish that goal. By definition, EBM practice guidelines recommend the safest and most effective treatments after unbiased assessment of the best available research. Increasingly, EBM is adopted to improve clinical and functional outcomes, establish national standards of care, and set criteria to evaluate clinical performance..$^{30}$

I Utilize established guidelines. A tactic that can make it easier to discuss return to work with patients is to rely on an independent and authoritative reference set of codified disability duration guidelines, which, typically, can be searched by diagnosis, procedure, or presenting symptoms. Such guidelines provide a condition-specific expected duration of work disability in the form of number of days, with shortest, typical, and maximum durations for different levels of job demands. If necessary, you can then adjust the guideline's estimated duration to account for the patient's age, underlying state of health, comorbidities, and so forth.

The use of disability duration guidelines at the point of care can facilitate the process of setting early and appropriate expectations for a patient's recovery. If a patient is confrontational in response to your recommendation on the duration of work disability, guidelines can be used to address specific objections and facilitate understanding of functional recovery.

I Consider the employer's needs. To support return-to-work efforts, your guidance about work should consider the employer's business needs. Employers require that the patient's abilities, restrictions, and limitations be described in concrete terms because they must decide which specific tasks are unsafe and which ones they can reasonably expect the recovering worker to perform. However, employers often fail to send information to the physician about the patient's job tasks-such that the clinician must rely on patient self-reporting, which might be inaccurate, incomplete, or biased. ${ }^{15}$ When a patient needs protection against foreseeable harm, highlight specific activities that are currently unsafe on the recovery timeline.

Employers rely on the physician to (1) estimate what the patient can do and (2) describe work ability in clear, objective terms that both patient and employer can interpret (TABLE). For example, "no heavy lifting" might be hard for an employer to interpret; "may lift 10 pounds from the floor to the waist as many as 12 times an hour" might be applied in a more practical manner to help a patient return to work safely. ${ }^{31}$ Including specific numbers, rates, and metrics in activity restrictions can also help demonstrate improvement over the course of treatment.

I Be clear and specific on work restrictions. During recovery, it is important to tell the patient which temporary work restrictions are intended to prevent further injury or recurrence (prophylactic work restrictions) 
TABLE

\section{Practical guidance for writing patient activity recommendations}

\begin{tabular}{l|l|l}
\hline Physician's action & Impact of that action & Example of action \\
\hline $\begin{array}{l}\text { Include specific numbers, rates, } \\
\text { and metrics }\end{array}$ & $\begin{array}{l}\text { Employer can appropriately define modified or } \\
\text { transitional duty to keep patient safe } \\
\text { Improvement over time can be measured during the } \\
\text { recovery period } \\
\text { Maximum medical improvement can be objectively } \\
\text { documented }\end{array}$ & $\begin{array}{l}\text { "May lift 10 lb from the ground to } \\
\text { waist level as many as } 12 \text { times an } \\
\text { work shift" }\end{array}$ \\
\hline $\begin{array}{l}\text { Explain limitations using } \\
\text { medical reasoning }\end{array}$ & $\begin{array}{l}\text { Provides guidance for activities that are not defined } \\
\text { for the physician, such as infrequent tasks or home } \\
\text { responsibilities }\end{array}$ & $\begin{array}{l}\text { "Prolonged standing (>2 h) might } \\
\text { cause injury" }\end{array}$ \\
\hline
\end{tabular}

and which are an estimate of what they are able to do safely at work (capacity-based restrictions). Your written work restrictions form should be kept separate from private medical information because those restrictions will be the basis of subsequent conversations between patient and employer, who should be invited to give feedback if the guidance needs revision or clarification.

I Employer programs, such as modified duty, transitional duty, or early return to work programs, have been found to resolve claims faster and improve recovery outcomes. ${ }^{10,12}$ Such programs might also reduce occupational stress and improve productivity when an employee realizes that their functional abilities are matched to realistic job expectations during recovery. ${ }^{16}$ You can play an important role in empowering your patients to seek out these support programs.

\section{What's ahead for managing disability durations?}

Work disability duration is influenced by the complex mix of biological, psychosocial, and economic variables that we have touched on here. All stakeholders involved in the recovery process should support the patient's ability to live life with as few restrictions as possible; you play a key role in their recovery by focusing on ability, highlighting remaining capabilities, emphasizing activities that are safe to perform, and encouraging acceptance of, and adaptation to, any irrevocable losses.

This is a holistic approach that might help patients overcome the stress and anxiety associated with major life events arising from illness or injury that trigger disability ben- efits. Open communication and establishing a shared goal, among all involved, of the best possible outcome increases the likelihood that working patients will return to their familiar life or find another positive path forward.

Using EBM and disability duration guidelines can help decrease the length of life-work disruption by ensuring that patients are given a diagnosis, treated, and managed appropriately. ${ }^{32,33}$ Although these practices have been adopted by some physicians, health care systems, and insurers, they are not being implemented systematically and are unlikely to become ubiquitous unless they are mandated by payers or by law.

Family physicians are front-line providers for America's workforce. They are distinctly situated to help patients achieve their best life at home and work. Improving the timeliness and quality of work guidance provided by the physician is an important way to minimize the impact of health problems on working people's lives and livelihoods-and to help them stay employed. JFP

CORRESPONDENCE

Kerri Wizner, MPH, 10355 Westmoor Drive, Westminster, CO 80021; kerri.wizner@mdguidelines.com.

\footnotetext{
References

1. Pransky G, Katz JN, Benjamin K, et al. Improving the physician role in evaluating work ability and managing disability: A survey of primary care practitioners. Disabil Rehabil. 2002;24:867-874. doi: 10.1080/09638280210142176

2. Hollenbeck K. Promoting Retention or Reemployment of Workers After a Significant Injury or Illness. Mathematica Policy Research; October 22, 2015. Accessed June 1, 2021. https://mathematica. org/publications/promoting-retention-or-reemployment-ofworkers-after-a-significant-injury-or-illness

3. Poor health costs us employers $\$ 530$ billion and 1.4 billion work days of absence and impaired performance according to
} 
Integrated Benefits Institute. Press release. November 15, 2018 Accessed June 1, 2021. www.ibiweb.org/poor-health-costs-usemployers-530-billion-and-1-4-billion-work-days-of-absenceand-impaired-performance

4. US Bureau of Labor Statistics. Life and disability insurance benefits: How extensive is the employer-provided safety net? BLS looks at life and disability benefits. Program Perspectives. 2010;2:7:1-4. Accessed June 8, 2021. www.bls.gov/opub/btn/ archive/program-perspectives-on-life-and-disability-insurancebenefits.pdf

5. Kettlewell N, Morris RW, Ho N, et al. The differential impact of major life events on cognitive and affective wellbeing. SSM Popul Health. 2019;10:100533. doi: 10.1016/j.ssmph.2019.100533

6. Contreary K, Ben-Shalom Y, Gifford B. Using predictive analytics for early identification of short-term disability claimants who exhaust their benefits. J Occup Rehabil. 2018;28:584-596. doi: 10.1007/s10926-018-9815-5

7. Hultin $\mathrm{H}$, Lindholm C, Möller J. Is there an association between long-term sick leave and disability pension and unemployment beyond the effect of health status? - A cohort study. PLoS One. 2012;7:e35614. doi: 10.1371/journal.pone.0035614

8. Canadian Medical Association. CMA policy: The treating physician's role in helping patients return to work after an illness or injury (update 2013); 2013:1-6. Accessed June 1, 2021. https:// policybase.cma.ca/documents/policypdf/PD13-05.pdf

9. Gifford B. Temporarily disabled workers account for a disproportionate share of health care payments. Health Aff (Millwood). 2017;36:245-249. doi:10.1377/hlthaff.2016.1013

10. Rueda S, Chambers L, Wilson M, et al. Association of returning to work with better health in working-aged adults: a systematic review. Am J Public Health. 2012;102:541-556. doi: 10.2105/ AJPH.2011.300401

11. Modini M, Joyce S, Mykletun A, et al. The mental health benefits of employment: results of a systematic meta-review. Australas Psychiatry. 2016;24:331-336. doi: 10.1177/1039856215618523

12. Shaw WS, Nelson CC, Woiszwillo MJ, et al. Early return to work has benefits for relief of back pain and functional recovery after controlling for multiple confounds. J Occup Environ Med. 2018;60:901-910. doi: 10.1097/JOM.0000000000001380

13. Jurisic M, Bean M, Harbaugh J, et al. The personal physician's role in helping patients with medical conditions stay at work or return to work. J Occup Environ Med. 2017;59:e125-e131. doi: 10.1097/ JOM.0000000000001055

14. World Health Organization. Towards a common language for functioning, disability and health. ICF: The International Classification of Functioning, Disability and Health. 2002. Accessed June 2, 2021. www.who.int/classifications/icf/icfbeginnersguide.pdf

15. Talmage JB, Melhorn JM, Hyman MH. AMA Guides to the Evalua tion of Work Ability and Return to Work. 2nd ed. American Medical Association; 2011.

16. Harrell M. Psychological factors and workforce health. In: Lee LP, Martin DW, Kancelbaum B. Occupational Medicine: A Basic Guide. American College of Occupational and Environmental Medicine; 2019. Accessed June 1, 2021. https://ohguides.acoem. org/07-psychological-factors-and-workforce-health-stressmanagement

17. Wickizer TM, Franklin GM, Fulton-Kehoe D. Innovations in occupational health care delivery can prevent entry into permanent disability: 8-year follow-up of the Washington State Centers for Occupational Health and Education. Med Care. 2018;56: 1018-1023. doi: 10.1097/MLR.0000000000000991

18. Christian J, Wickizer T, Burton K. Implementing a community- focused health \& work service. SSDI Solution Initiative, Fisca Institute of the Committee for a Responsible Federal Budget. May 2019. Accessed June 2, 2021. www.crfb.org/sites/default/files/ Implementing_a_Community-Focused_HWS.pdf

19. Macpherson RA, Koehoorn M, Fan J, et al. Do differences in work disability duration between men and women vary by province in Canada? J Occup Rehabil. 2018;29:560-568. doi: 10.1007/ s10926-018-9819-1

20. Rainville J, Pransky G, Indahl A, et al. The physician as disability advisor for patients with musculoskeletal complaints. Spine (Phila Pa 1976). 2005;30:2579-2584. doi: 10.1097/ 01.brs.0000186589.69382.1d

21. Jay K, Thorsen SV, Sundstrup E, et al. Fear avoidance beliefs and risk of long-term sickness absence: prospective cohort study among workers with musculoskeletal pain. Pain Res Treat. 2018;2018:8347120. doi: 10.1155/2018/8347120

22. Burgard S, Lin KY. Bad jobs, bad health? How work and working conditions contribute to health disparities. Am Behav Sci. 2013; 57:10.1177/0002764213487347. doi: 10.1177/0002764213487347

23. Soklaridis S, Tang G, Cartmill C, et al. "Can you go back to work?" Family physicians' experiences with assessing patients' functional ability to return to work. Can Fam Physician. 2011;57:202-209.

24. Peters SE, Truong AP, Johnston V. Stakeholders identify simila barriers but different strategies to facilitate return-to-work: a vignette of a worker with an upper extremity condition. Work 2018;59:401-412. doi: 10.3233/WOR-182692

25. Shraim M, Cifuentes M, Willetts JL, et al. Regional socioeconomic disparities in outcomes for workers with low back pain in the United States. Am J Ind Med. 2017;60:472-483. doi: 10.1002/ ajim.22712

26. Hill JC, Fritz JM. Psychosocial influences on low back pain, disability, and response to treatment. Phys Ther. 2011;91:712-721. doi: $10.2522 /$ ptj.20100280

27. Aasdahl L, Pape K, Jensen C, et al. Associations between the readiness for return to work scale and return to work: a prospective study. J Occup Rehabil. 2018;28:97-106. doi: 10.1007/ s10926-017-9705-2

28. Pino C, Covington M. Prescription of opioids for acute pain in opioid naïve patients. UpToDate Web site. February 9 , 2021. Accessed June 2, 2021. www.uptodate.com/contents/ prescription-of-opioids-for-acute-pain-in-opioid-naive-patients

29. Cancelliere C, Donovan J, Stochkendahl MJ, et al. Factors affecting return to work after injury or illness: best evidence synthesis of systematic reviews. Chiropr Man Therap. 2016;24:32. doi: 10.1186/s12998-016-0113-z

30. Lewis SJ, Orland BI. The importance and impact of evidencebased medicine. J Manag Care Pharm. 2004;10(5 suppl A):S3-S5. doi: 10.18553/jmcp.2004.10.S5-A.S3

31. Rupe KL. Work restrictions: documenting a patient's re turn to work. Nurse Pract. 2010;35:49-53. doi: 10.1097/01. NPR.0000388901.49604.a8

32. Owens JD, Hegmann KT, Thiese MS, et al. Impacts of adherence to evidence-based medicine guidelines for the management of acute low back pain on costs of worker's compensation claims. J Occup Environ Med. 2019;61:445-452. doi: 10.1097/ JOM.0000000000001593

33. Gaspar FW, Kownacki R, Zaidel CS, et al. Reducing disability durations and medical costs for patients with a carpal tunne release surgery through the use of opioid prescribing guidelines. J Occup Environ Med. 2017;59:1180-1187. doi: 10.1097/ JOM.0000000000001168

\section{Keep the} patient's attention on the positive process of recovery, and document evidence of functional progress. 